\title{
STRUCTURAL ANALYSIS APPLICATIONS
}

\author{
R. L. MoKnight \\ General Electric AEBG \\ Cincinnati, Ohio
}

\section{ABSTRACT}

The programs in the structural analysis area of the HOST program emphasized the generation of computer codes for performing three-dimensional inelastic analysis with more accuracy and less manpower. This paper presents the application of that technology to Aircraft Gas Turbine Engine (AGTE) components; combustors, turbine blades, and vanes. Previous limitations will be reviewed and the breakthrough technology highlighted. The synergism and spillover of the program will be demonstrated by reviewing applications to thermal barrier coatings analysis and the SSME HPFTP turbine blade. These applications show that this technology has increased the ability of the AGTE designer to be more innovative, productive, and accurate.

\section{INTRODUCTION}

The activities of the NASA Turbine Engine Hot Section Technology Project were directed toward functionality and durability needs of AGTE hot section components - the combustor, turbine vanes, and turbine blades. The overall approach of this program was to assess the existing analysis methods for strengths and deficiencles, and then to conduct supporting analytical and experimental research to rectify those deficiencies and, at the same time, incorporate state-of-the-art improvements into the analysis methods.

Structural analysis has two major objectives in the design of AGTE's. The first major objective is to generate and verify a functional design. The second major objective is to quantify the durabilityl reliability of these designs. The first objective can be accomplished by analyzing candidate designs for a simplified mission cycle - the maximum envelope of the technical requirements. Evaluations are made by comparing the code outputs - displacements, stresses, and strains - against technical requirements and design practices. The second objective requires that the entire mission cycle be analyzed and the code output be combined with durability/reliability technology in a postprocessing operation.
For both of these types of analyses, some portion of the airframe-engine system is mathematically simulated and a history of the operating environment and interaction effects of the remainder of the system imposed as loads and boundary conditions. For functionality the simpler-maximum history can be imposed on a larger portion of the overall system. Since durability/reliability is a point function, smaller portions of the system must be run through the total complex history of loading. For both of these analyses, the loading, environment, and interactions are provided to the analyst from other "expert" groups. A deficiency common to both types of analyses is that of economy/productivity as measured by the total period of time, number of man-hours, and the computer resources required to complete a design analysis. For functional analyses, the second major deficiency was due to the combination of the formulation models (Finite-Element Model, Finite Difference Model, Boundary Element Model) and the numerical accuracy of the computer. These limitations affected the ability to accurately simulate large systems with their complex interactions without exceptionally fine modeling. For durability/reliability analyses, the second major deflclency was the inability of the combination of the formulation models, constitutive models, and the numerical accuracy of the computer to accurately simulate the local inelastic material behavior. This deficiency was particularly evident in the hot section components exposed to the severe thermal and mechanical operating environments of the AGTE. The local, durability limiting, areas of these structures are exposed to time varying temperature distribution which affect both the material properties and the thermal and mechanical stresses in a complex three-dimensional manner.

The HOST program successfully accomplished its goals by attacking the above deficiencies. This was done through a series of programs in which were developed constitutive models, three-dimensional inelastic structural analysis codes, a three-dimensional thermal 
transfer code, and a component specific modeling system. The application of these advanced tools was almost simultaneous with their development. The remainder of this paper will present selective applications of these technologies.

\section{Combustor Design and Analysis}

The combustor is one of the most challenging and complex components of the AGTE. Its design involves many "expert" groups; controls, fuel nozzles, chemical combustion kinetics, heat transfer, and structures. It presents one of the major productivity drains in AGTE designs, both for initial design and for subsequent tuning for mission variations. HOST attacked all aspects of this problem, economy/productivity as well as accuracy, in the component specific modeling effort. In this program the many diverse disciplines which impact on a combustor liner design were integrated into a component specific system utilizing the HOST technologies.

The COSMO computer system consists of a Thermodynamic Engine Model (TOEM), a Thermomechanical Load Model (TDLM), and Combustor Structural Model. The TDEM generates the engine internal flow variables for any point in the operating mission by the specification of three variables, altitude ( $h$ ), Mach number $(M)$, and power level ( $P L$ ) for the allowed flight map of an engine, as shown in Fig. 1. Additional control variables are amblent temperature deviations from the standard atmosphere, airframe bleed air requirements, and engine deterioration. For each input condition, specified by $h, M$, and $P L$ the TDEM calculates gas weight flow $(w)$, temperature $(t)$, and pressure $(p)$ for the combustor.

The TDEM technique is shown in Figs. 2 to 4 . The engine to be analyzed must have its aerodynamic stations ( $F i g .2$ ) defined thermodynamically by an engine cycle deck (computer program) which can be run to generate the internal flow variables at chosen aerodynamic stations ( $F i g .3$ ). In COSMO the complete engine operating map ( $F$ ig. 1 ) is encompassed by selecting 148 operating points for which $w, t, p$ as well as $N_{1}$ and $\mathrm{N}_{2}$, the fan and core speeds, are calculated for the stations pertinent to the COSMO components.

From this station data an Engine Performance Cycle Map is constructed. This is essentially a set of three-dimensional data arrays which map the station data $\left(w, t, p, n_{1}\right.$, and $N_{2}$ ) on to the engine operating map ( $F i g$. i). Given an arbitrary operating point defined by $h, M$, and $P L$ it is then, in principle, possible to interpolate on the engine performance cycle map to determine station data. These station parameters are nonlinear functions of the input parameters and much effort went into the development of these multidimensional interpolation techniques.

The functioning of the TDEM is shown in Fig. 4. Given an engine mission, as shown schematically in Fig. 5 , it can be defined by values of the input variables $h, M$, and $P L$ at selected times through the mission. Using these input variables and the Engine Performance Cycle Map the interpolation program calculates engine station parameters throughout the mission ( $\mathrm{Fig.} \mathrm{4)}$. These are then used to define the station mission proflles of $w, t, p, N_{1}$, and $N_{2}$ as functions of time at each aerodynamic station. These station mission profiles then become the input to the TDLM.

The TDLM is the computer program which works with the output of the TDEM to produce the mission cycle loading on the individual hot section components, in this case the combustor. This software translates the major engine performance parameter profiles from the TDEM into profiles of the components thermodynamic loads (pressures, temperatures, rpm). The formulas which perform this mapping in the TOLM models were developed for the specific engine components of the CF6-50C engine. To adapt these models to a different engine would require the evaluation of these formulas for their simulation capability and reformulating where necessary.

The heart of the component specific structural modeling is geometric modeling and mesh generation using the recipe concept. A generic geometry pattern is determined for each component. A recipe is developed for this basic geometry in terms of point coordinates, lengths, thicknesses, angles, and radi $i$.

Figures 6 to 8 show this process for a rolled ring combustor. These recipe parameters are encoded in computer software as variable input parameters with a set of default numerical values defined. Figure 9 defines the recipe which generates the combustor structural mode 1 .

A snapshot of a typical run of the combustor model is shown in Fig. 10. As indicated, the model contains a default set of recipe parameters, only changes to this list need be given. After the recipe parameters have been set, only five parameters need be specified to generate a three-dimensional sector model of a combustor to perform a hot streak analysis. The first parameter (shown as the number of exhaust nozzles) is required to divide the $360^{\circ}$ combustor into the proper number of sectors. The next parameter (shown as the number of circumferential elements) is used by the analyst to split up the circumferential sector into a number of slices, NS, for the three-dimensional elements and bias these slices by spectfying NS-1 percents.

For the particular case involved three exhaust nozzles are specified with four circumferential elements. These circumferential elements are then biased, starting at the hot streak, as 5, 15, and 30 percent. This leaves the final slice to be 50 percent. This is al1 the information required to generate a threedimensional finite-element model consisting of 20-noded isoparametric finite elements. In this case the model consists of 648 elements, 3192 nodes, and has 768 element faces with pressure loading. Figures 11 and 12 are graphical depictions of this three-dimensional model. The temperatures and pressures from the TDLM are mapped onto this model and the necessary data files are generated for a nonlinear structural analysis.

The subsystem which performs the three-dimensional nonlinear finite-element analysis of the combustor model was that developed in the HOST program, "Threedimensional Inelastic Analysis Methods for Hot Section Structures." This software performs incremental nonlinear finite-element analys is of complex threedimensional structures under cyclic thermomechanical loading with temperature dependent material properties and material response behavior. The nonlinear analys is considers both time independent and time dependent material behavior. Among the constitutive models available are a simplified model, a classical model, and a unifled model. A major advance in the ability to perform time dependent analyses is the dynamic time incrementing strategy incorporated in this software.

The COSMO system consists of an executive module which controls the TDEM, TDLM, the geometric modeler, the structural analysis code, the file structure/data base, and certain ancillary modules. These ancillary modules consist of a bandwidth optimizer module, a deck generation module, a remeshing/mesh refinement module, and a postprocessing module. The executive directs the running of each module, controls the flow of data among modules and contains the self-adaptive control logic. Figure 13 is a flow chart of the COSMO system showing the data flow and the action positions of the adaptive 
controls. The modular design of the system allows each subsystem to be viewed as a plug-in module which can be replaced with alternates.

The ideas, techniques, and computer software contained in COSMO have proven to be extremely valuable in advancing the productivity and design analysis capability of combustors. This software in conjunction with modern supercomputers is able to reduce a design task which previously required man-months of effort over a time period of months to a one-man, less than a day effort. Along with this time compression comes increased accuracy from the advanced modeling and analysis techniques. As a result of this, more analytical design studies can be performed, reducing the chances for field surprises and the amount of combustor testing required.

\section{Turbine Blade Analys is}

The analysis of turbine blades is an excellent barometer of the improvements brought about by the HOST program. There was a pre-HOST program called, "Turbine Blade Tip Durability Analysis, "which established the state-of-the-art prior to HOST. A commercial aircooled turbine blade with a well-documented history of cracking in the squealer tip region was subjected to cyclic nonlinear analysis by a commercially available computer program, ANSYS. This three-dimensional problem had previousiy been analyzed, elastically, by an in-house computer program. At the end of the HOST program, this problem was once again used to establish the changes brought about by HOST.

The problem involved was the significant creepfatigue encountered in a Stage- 1 high-pressure turbine blade. These blades are hollow, a fr-cooled, and paired together on a single three-tang dovetail. Figure 14 shows one such blade and indicates the region of analysis. The three-dimensional finite-element model of the component blade tip above the 75-percent span was constructed of 580 eight-noded isoparametric brick elements with 1119 nodes. A detailed, exploded view of this model depicting the squealer tip, tip cap, and spar as discrete three-dimensional components is shown in Fig. 15.

This ANSYS model was exercised on the CDC- 7600 computer. This model had previousiy been run on the TAMP-MASS computer program and the Honeywell 6000 computer. In 1986, this model was converted to 580 . 20-noded isoparametric finite elements and run on one of the codes developed under, "Three-Dimensional Inelastic Analysis Methods for Hot Section Structures." Table 1 shows the times and costs experienced under the varlous conditions. The impact of the advancements in technology and computer hardware is apparent from this table.

\section{Thermal Barrier Coating Analysis}

Another technological area in the HOST program was that of "Surface Protection." Programs were developed under this area to produce an understanding and to generate theories and computer tools for the design, analysis, and life prediction of Thermal Barrier Coatings (TBC). Figure 16 shows one type of test specimen involved in this effort. Figure 17 shows the axisymmetric finite-element model used to simulate these test specimens. Figure 18 is a furnace thermal test cycle these specimens were cycled through. Figures 19 and 20 are representative analytical results for the critical life locations.

Without the developments in the structural analysis area of HOST this test simulation would not have been attempted because of the excessive amounts of computer time that would have been required. This problem is highly time dependent and numerically sensitive. The material properties and the creep properties differ greatly among the three constituents of this material system. An added nonlinearity occurs due to the growth of an oxide scale between the bond coat and the top coat. The dynamic time incrementing algorithm developed under the three-dimensional inelastic HOST program made the analysis of this nonlinear system possible.

\section{SSME HPFTP Turbine Blade}

One final example of the application of HOST technology is the NASA program with the acronym - SADCALM. This stands for, "Structural Analys is Demonstration of Constitutive and Life Models." Under this program, coated single crystal turbine blades such as the one indicated in Fig. 21 will be analyzed by the most advanced technology developed under HOST. This includes the 20-noded isoparametric finite element and the constitutive models developed in the threedimensional inelastic programs. The single crystalcrystallographic constitutive model developed under the anisotropic constitutive modeling programs, and three HOST life theories, "Cyclic Damage Accumulation," "Total Strain-Strain Range Partitioning," and "Hysteretic Energy," will be used. This program involves testing, analysis, and correlation and will provide an excellent opportunity for demonstrating the benefits of the HOST program.

\section{CONCLUSIONS}

The ideas, techniques, and computer software developed under the NASA HOST program have proven to be extremely valuable in advancing the productivity and design analysis capability for hot section structures of AGTE's. This software in conjunction with modern supercomputers is able to reduce a design task significantiy. These ideas are amenable to further generalization/specialization and extension to all areas of the engine structure. These techniques will have their major payoff in the next generation of aerospace propulsion systems with their increasingly large number of parametric variations.

\section{REFERENCES}

Maffeo, R., 1985, "Burner Liner Thermal/Structural Load Modeling, TRANCITS Program User's Manual," NASA CR-174891.

McKnight, R.L., 1983, "Component Specific Modeling; First Annual Status Report," NASA CR-174765.

McKnight, R.L., 1985, "Component Specific Modeling: Second Annual Status Report," NASA CR-174925.

MCKnight, R.L., Laflen, J.H. . Halford, G.R., and Kaufman, A., 1983, "Turbine Blade Nonlinear Structural and Life Analysis," Journal of Aircraft, Vol. 20. No. 5, pp. 475-480.

McKnight, R.L., Laflen, J.H., and Spamer, G.T., 1981. "Turbine Blade Tip Durability Analysis," NASA CR-165268. 
TABLE 1. - TURBINE BLADE TIP MODEL HISTORY

\begin{tabular}{|c|c|c|c|c|c|}
\hline Year & $\begin{array}{l}\text { Computer } \\
\text { program }\end{array}$ & Finite element & Computer & $\begin{array}{l}\text { Wall } \\
\text { time }\end{array}$ & $\begin{array}{l}\text { Computer } \\
\text { time }\end{array}$ \\
\hline 1975 & TAMP-MASS & $\begin{array}{c}8 \text {-noded } \\
\text { isoparametric }\end{array}$ & $\begin{array}{l}\text { Honeywe } 11 \\
6000\end{array}$ & $60 \mathrm{hr}$ & $20 \mathrm{hr}$ \\
\hline 1981 & ANSYS & $\begin{array}{c}8 \text {-noded } \\
\text { i soparametric }\end{array}$ & $\mathrm{CDC}-7600$ & $24 \mathrm{hr}$ & $3 \mathrm{hr}$ \\
\hline 1986 & $\begin{array}{c}\text { HOST } \\
\text { three- } \\
\text { dimensional } \\
\text { inelastic }\end{array}$ & $\begin{array}{c}20 \text {-noded } \\
\text { i soparametric }\end{array}$ & CRAY - 1 & $115 \mathrm{sec}$ & $114 \mathrm{sec}$ \\
\hline
\end{tabular}

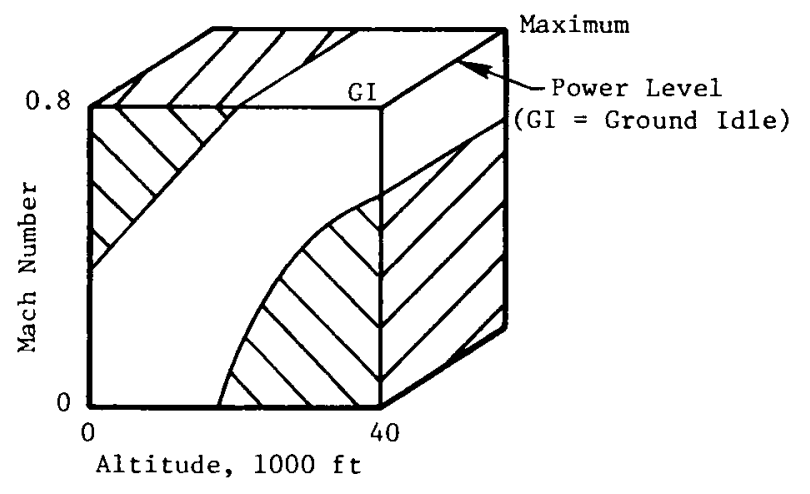

Figure 1. Engine Operating Map. 


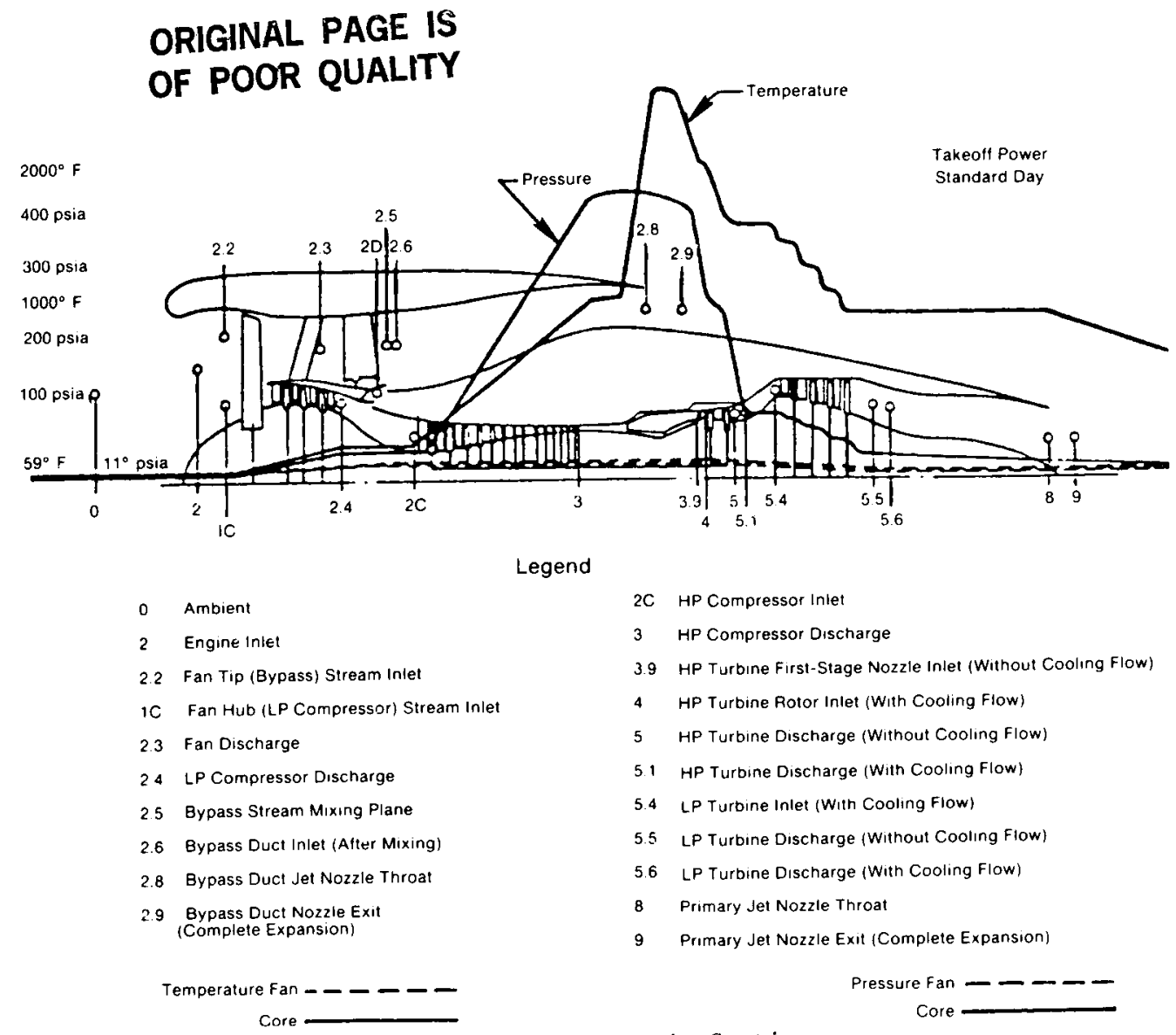

Figure 2. Aerodynamic Stations.

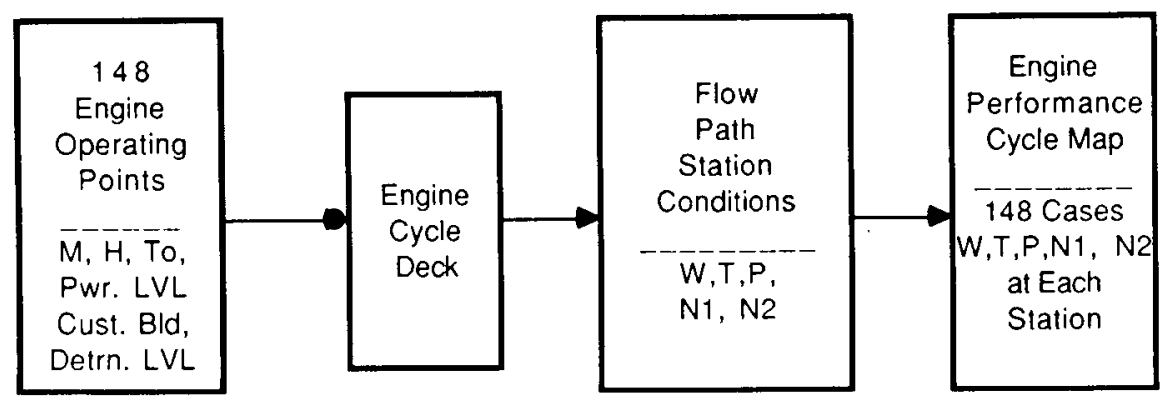

Figure 3. Thermodynamic Engine Model Cycle Map Generation.

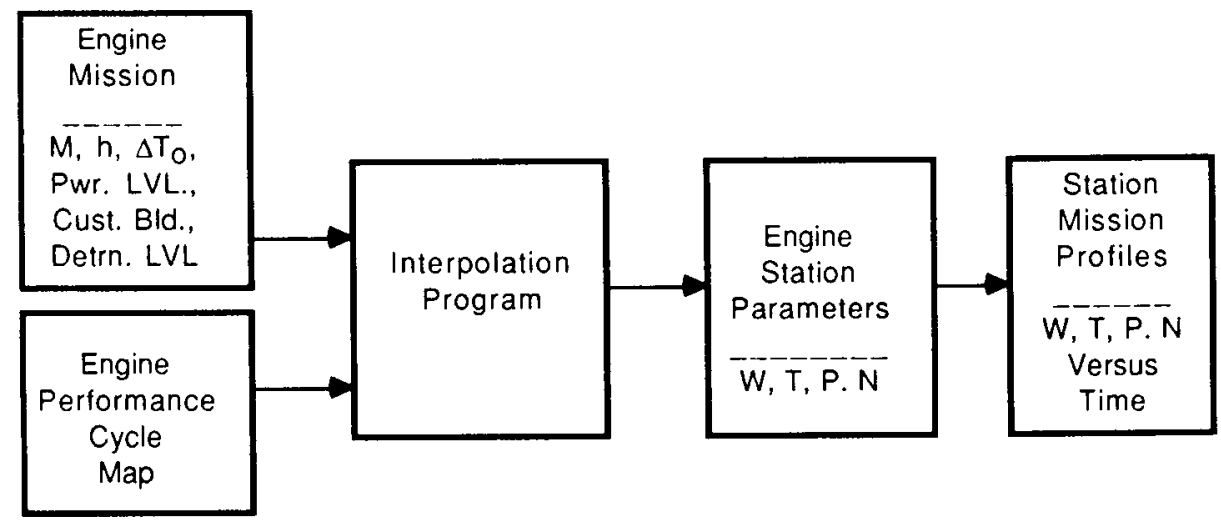

Figure 4. Thermodynamic Engine Model. 


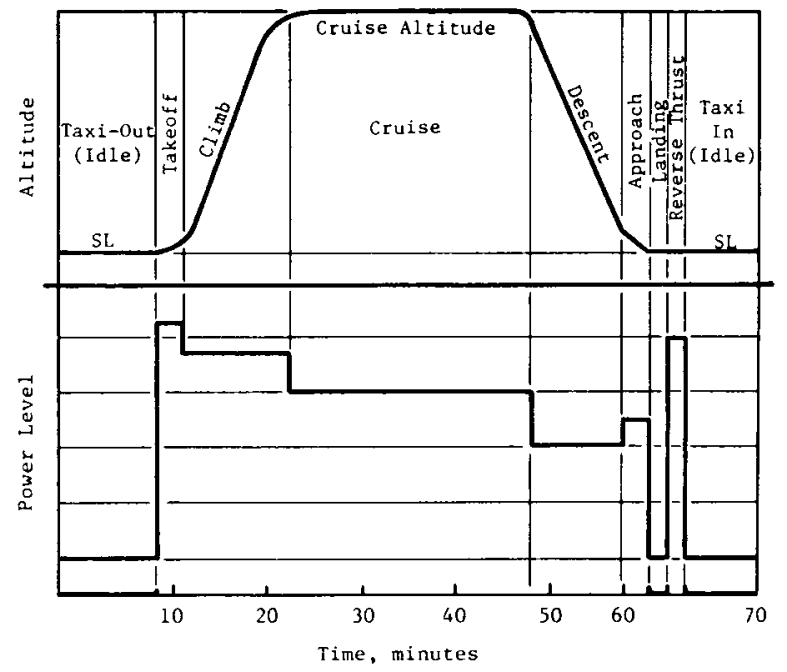

Figure 5. Typical Flight Cycle.

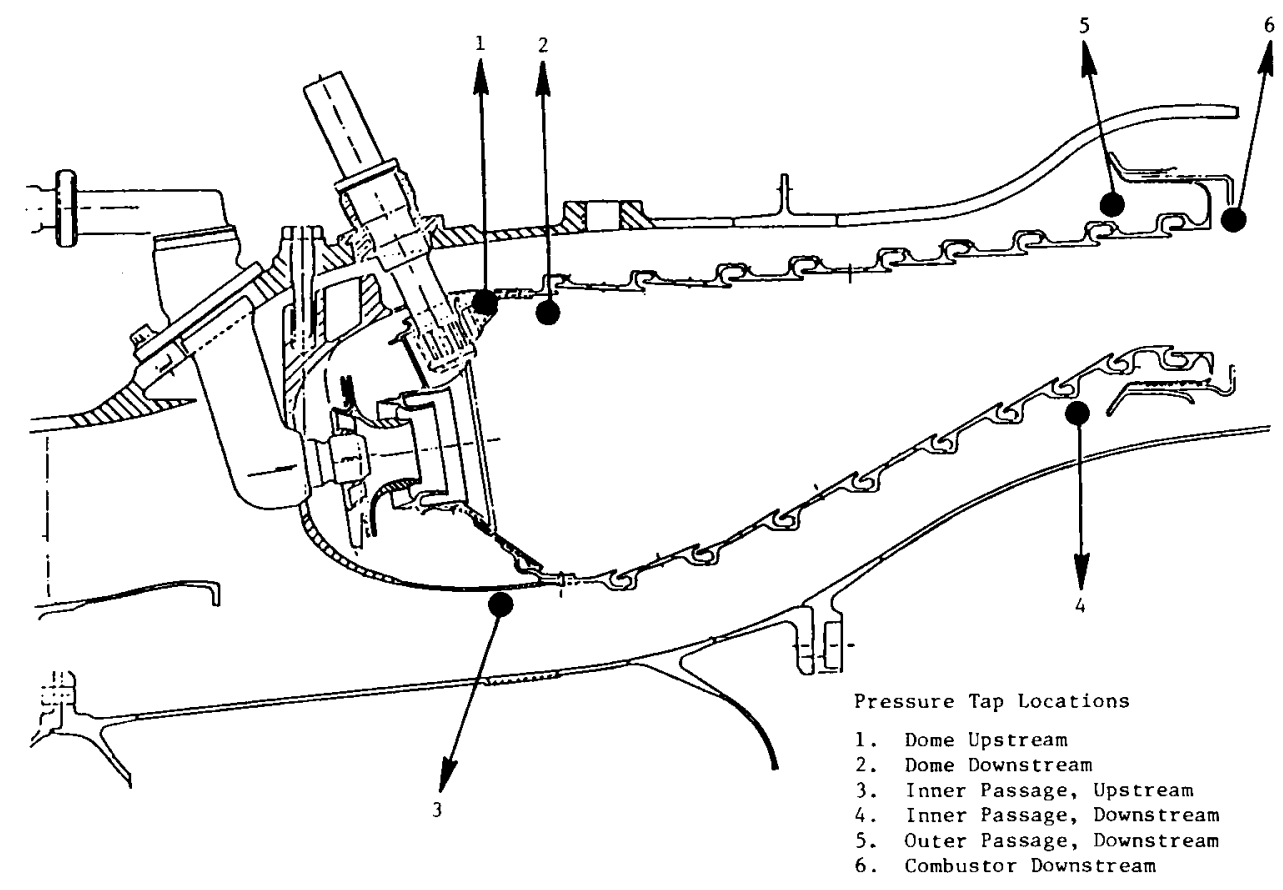

Figure 6. Rolled Ring Combustor. 


\section{ORIGINAL PAGE IS
OF POOR QUALITY}

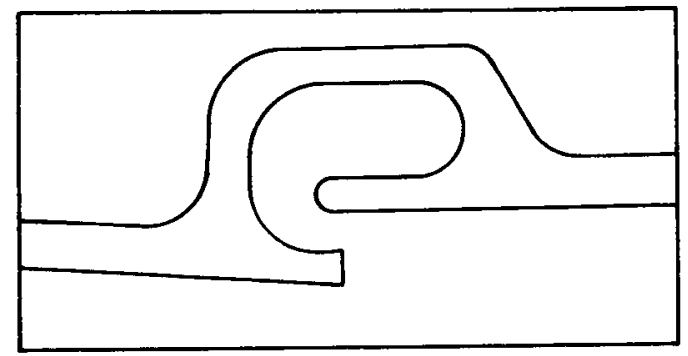

Typical Nugget

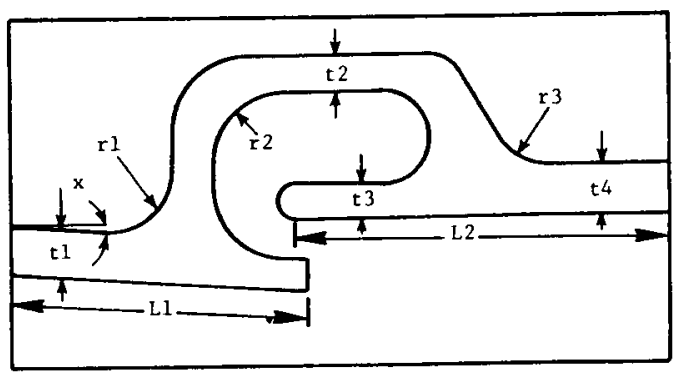

Physical Input Parameters

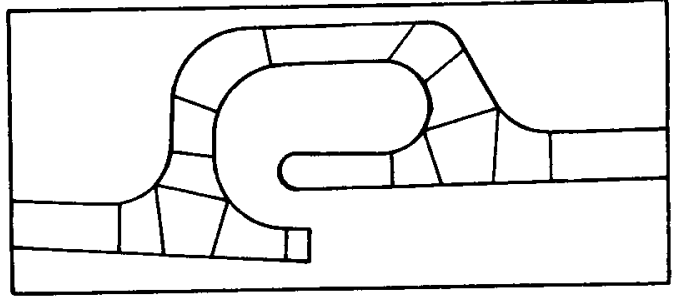

Master Region Definition

Figure 7. Combustor Recipe Process.

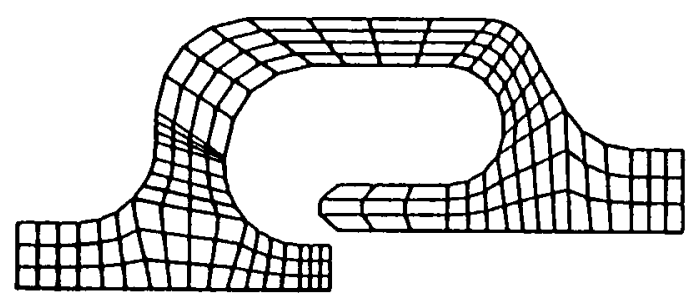

2D Mode 1

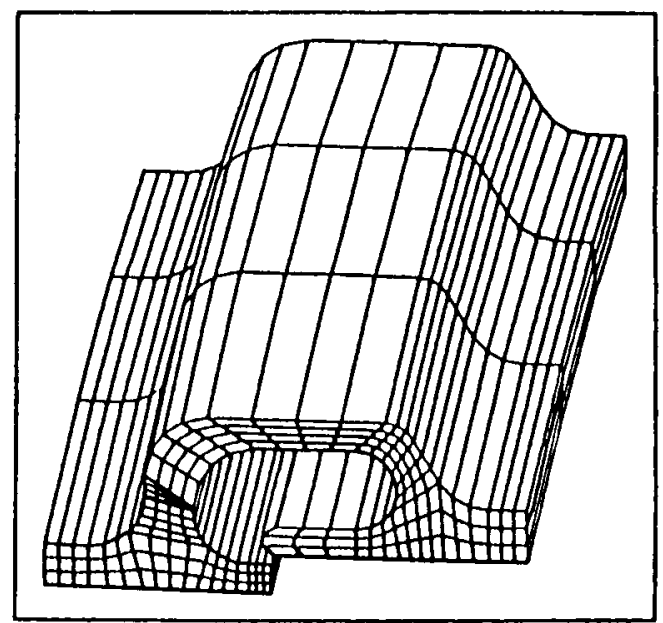

3D Moiel

Figure 8. Combustor Nugget Finite Element Models.

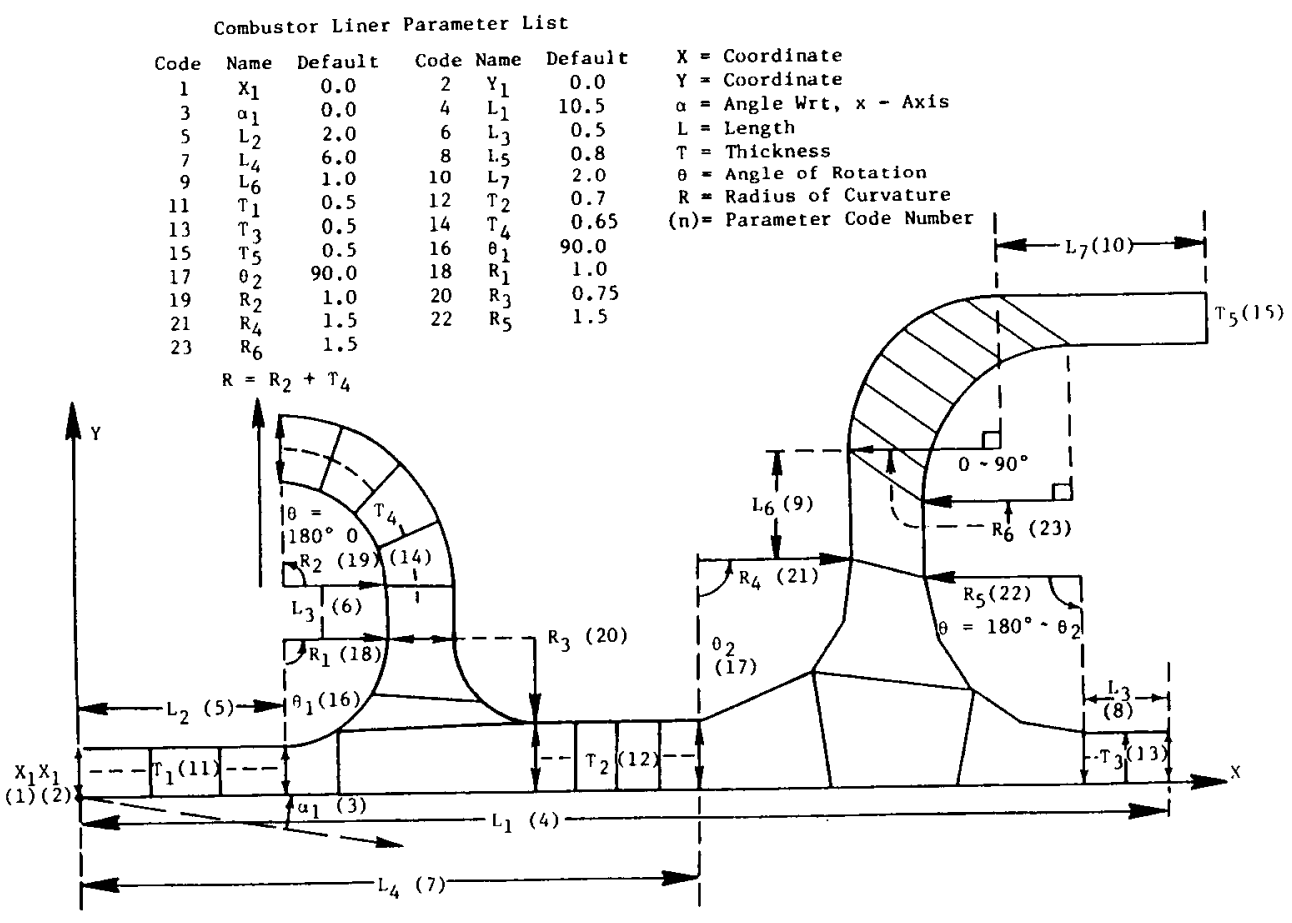

Figure 9. Combustor Liner Parameters. 


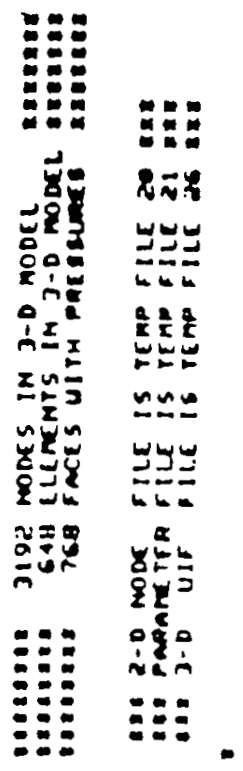

\author{
ORIGINAL PAGE IS \\ OF POOR QUALITY
}
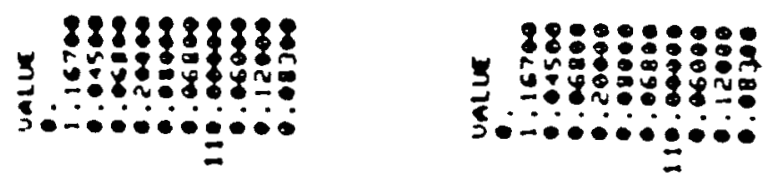

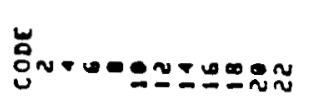
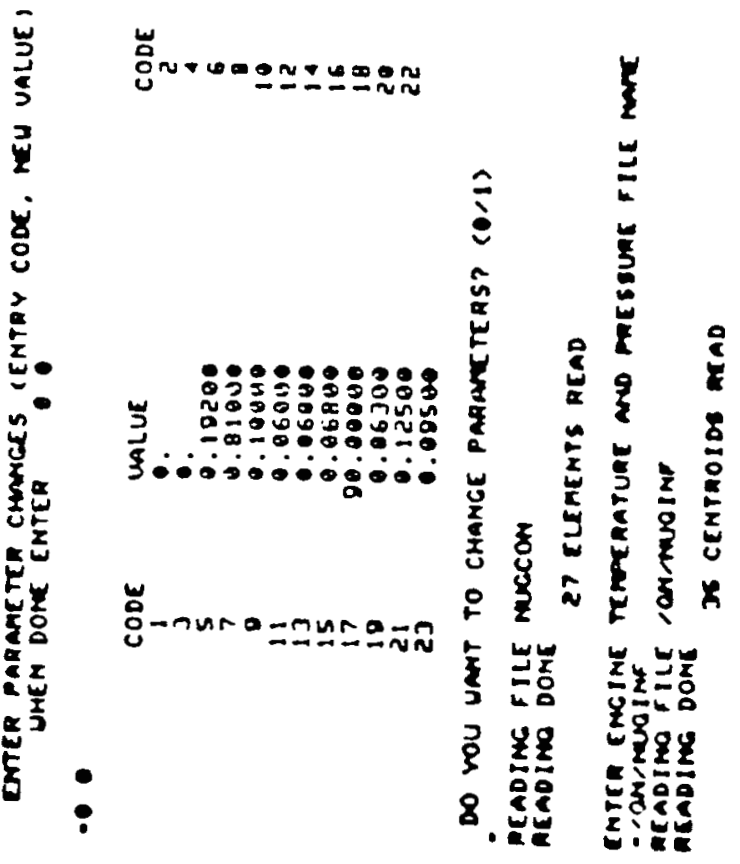

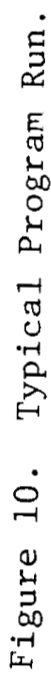

ไิ่

$\therefore$

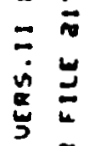

点

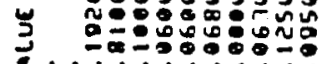

10.0.0.

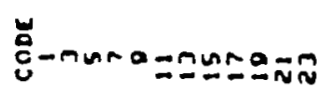

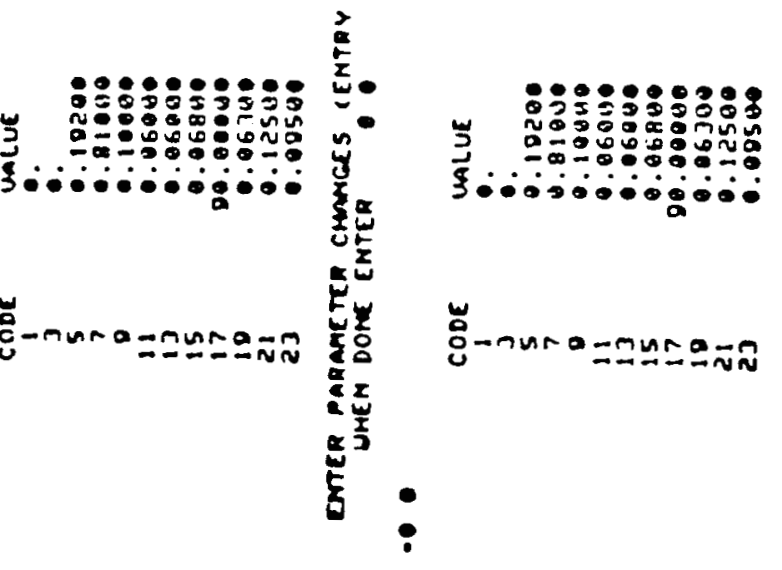

8.

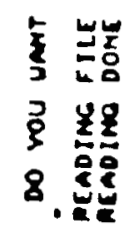

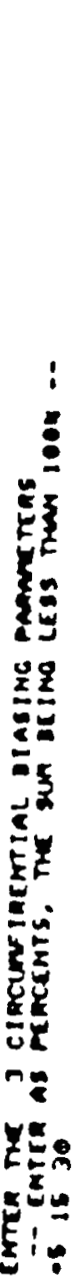




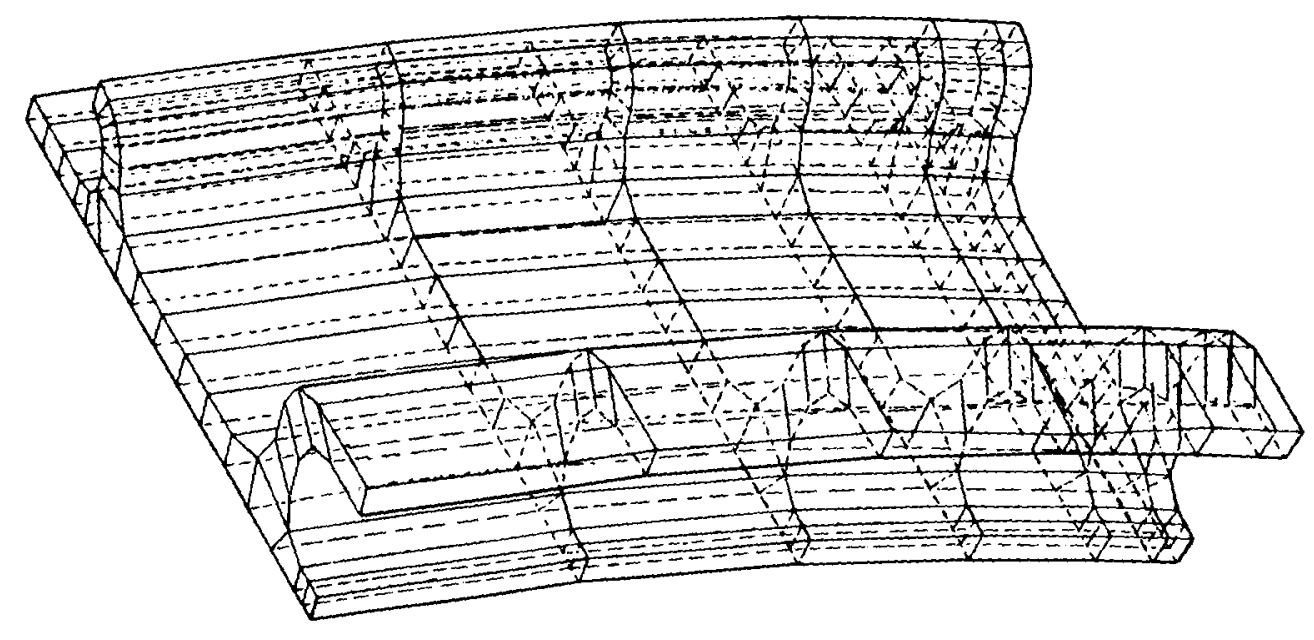

Figure 11. 3D Model Layout.

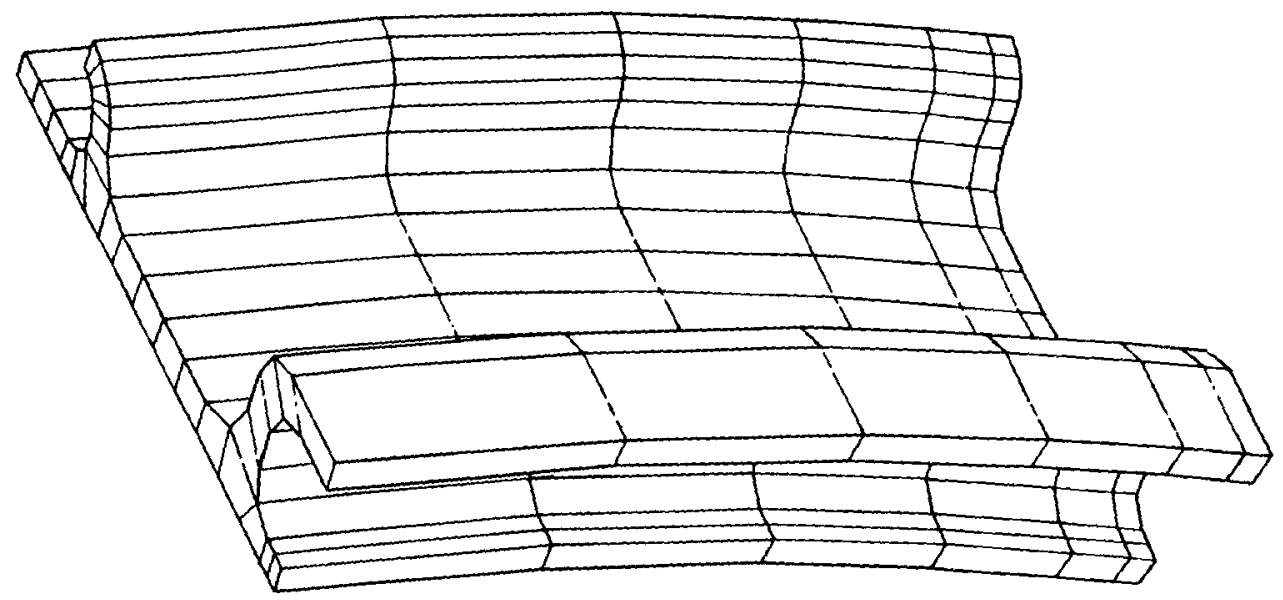

Figure 12. Hidden Line Plot of 3D ModeI. 

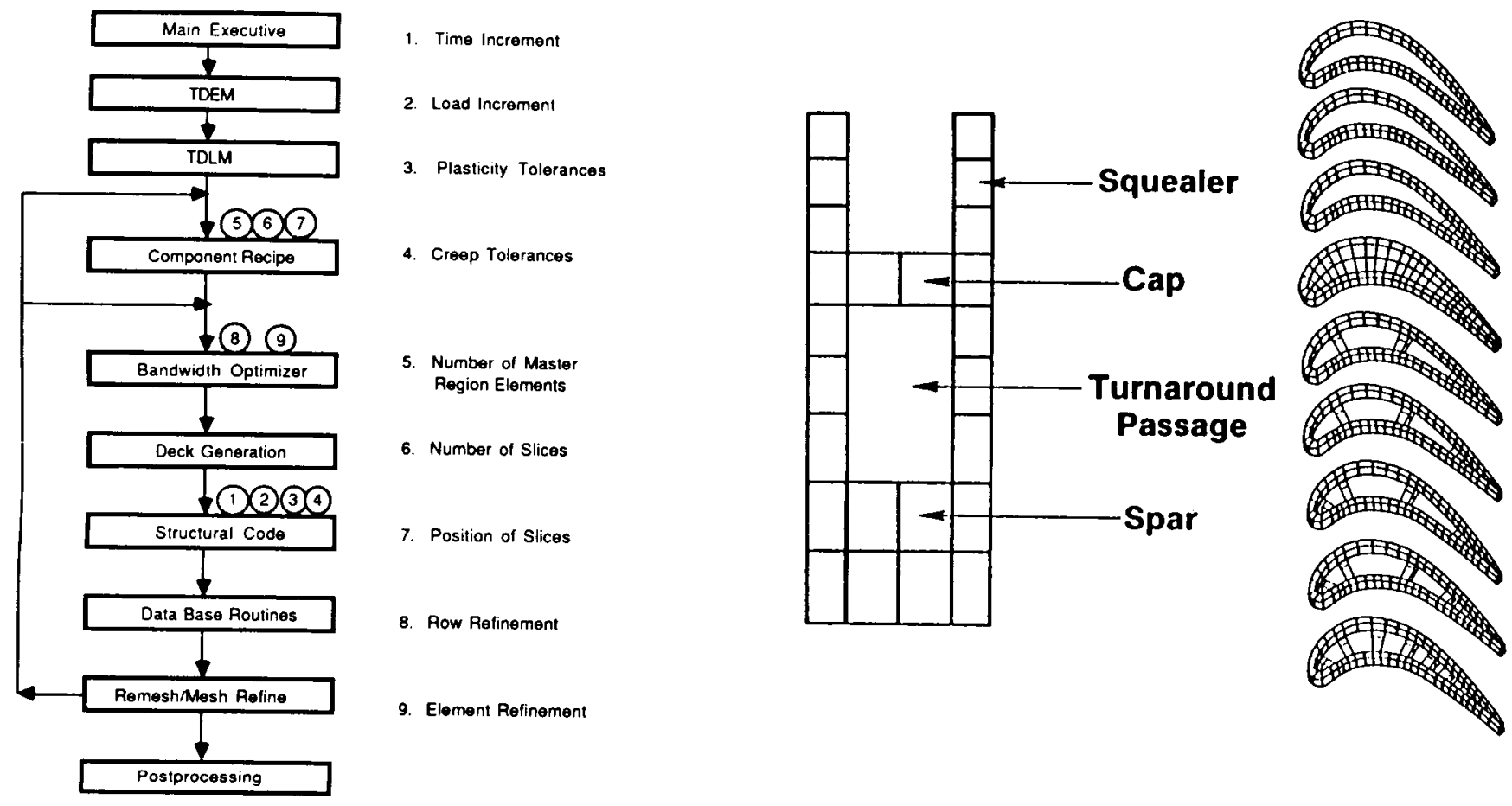

Figure 15. Finite Element Model of Blade Tip.

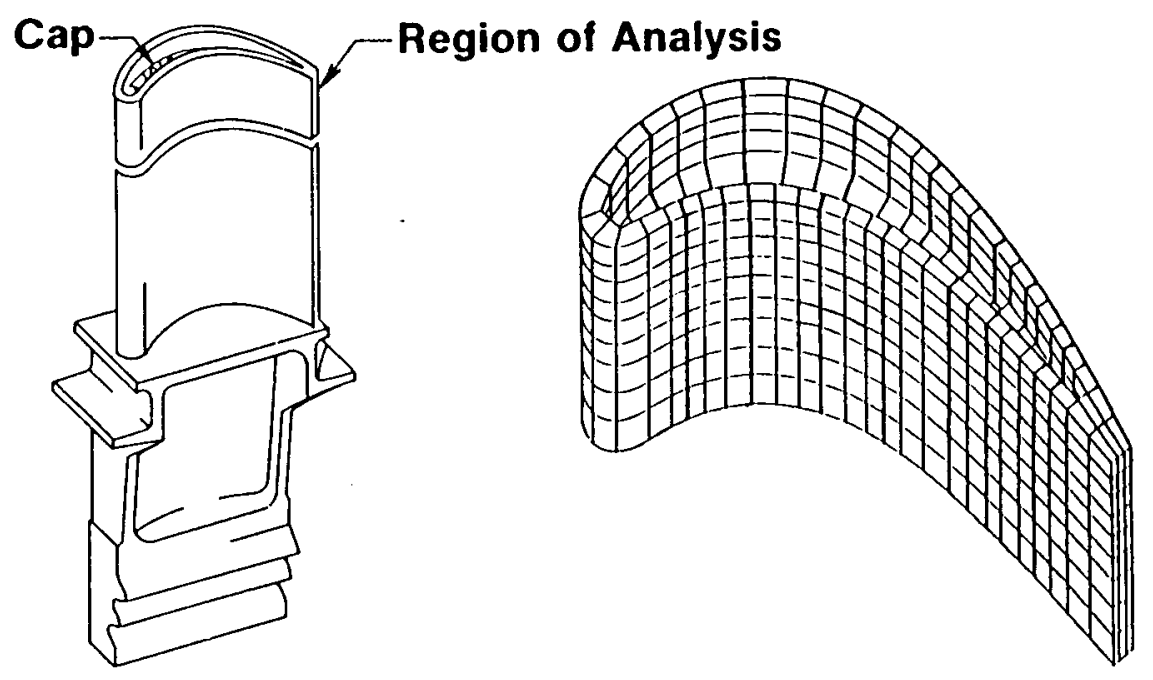

Figure 14. Stage 1 High Pressure Turbine Blade and Finite Element Model. 


\section{ORIGINAL PAGE IS \\ OF POOR QUALITY}

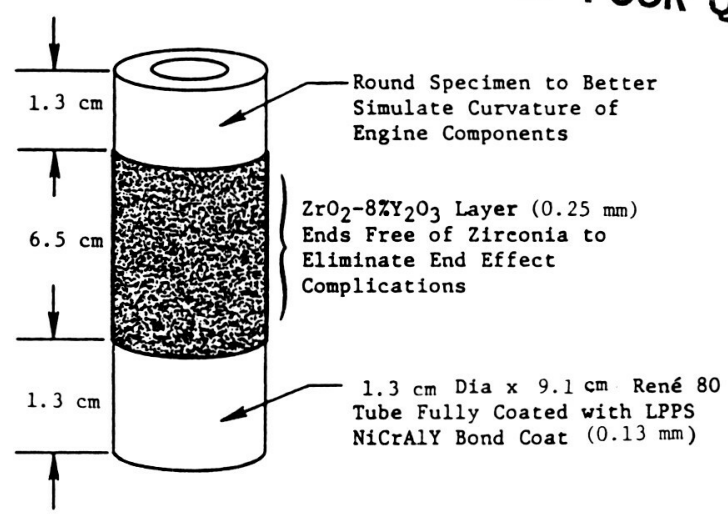

(a) Test Specimen Configuration

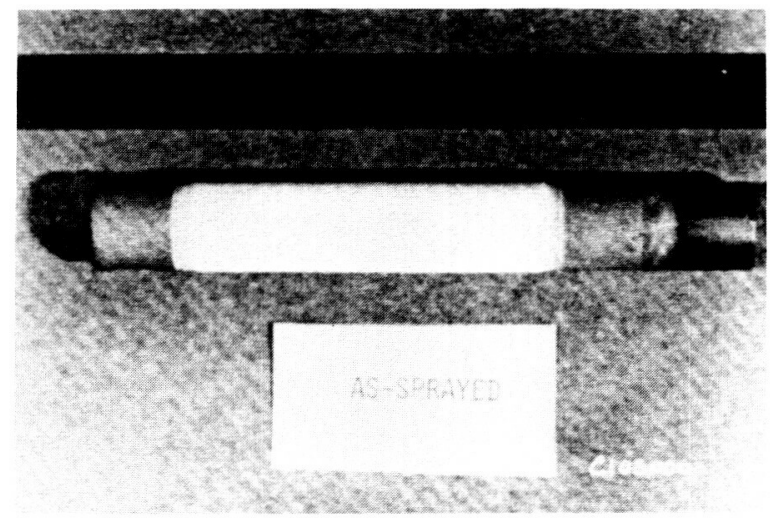

(b) As-Sprayed Specimen

Figure 16. Thermal Barrier Coated Tubular Specimen.

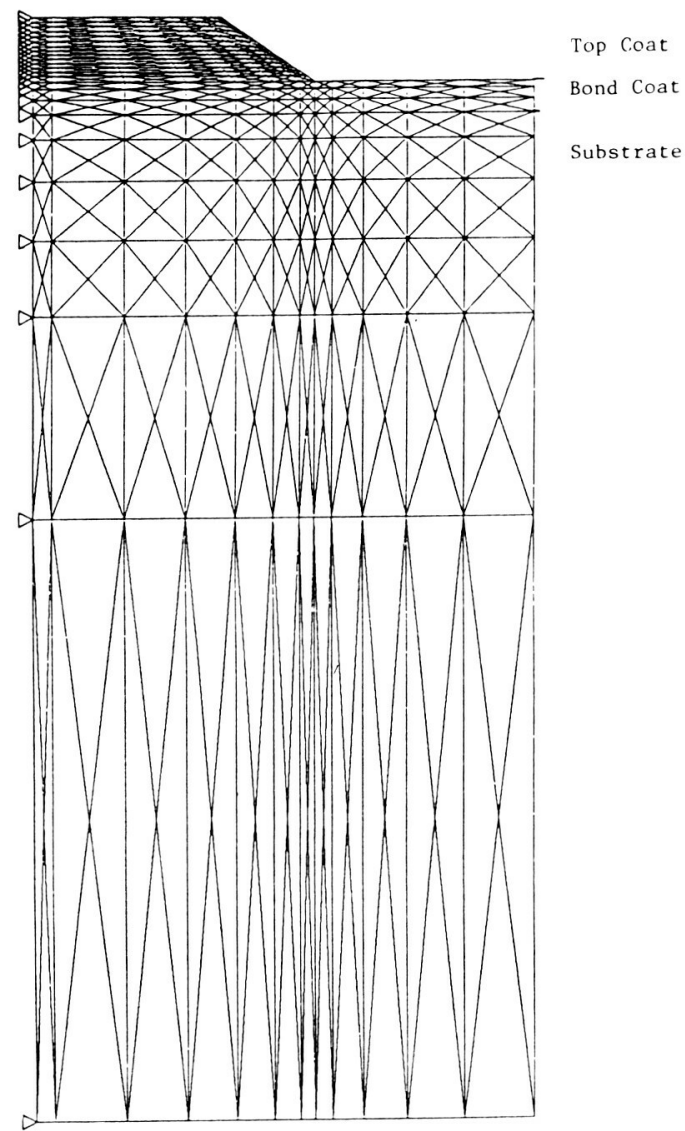

Figure 17. Finite Element Mesh for Thermal Barrier Coated Tubular Specimens.

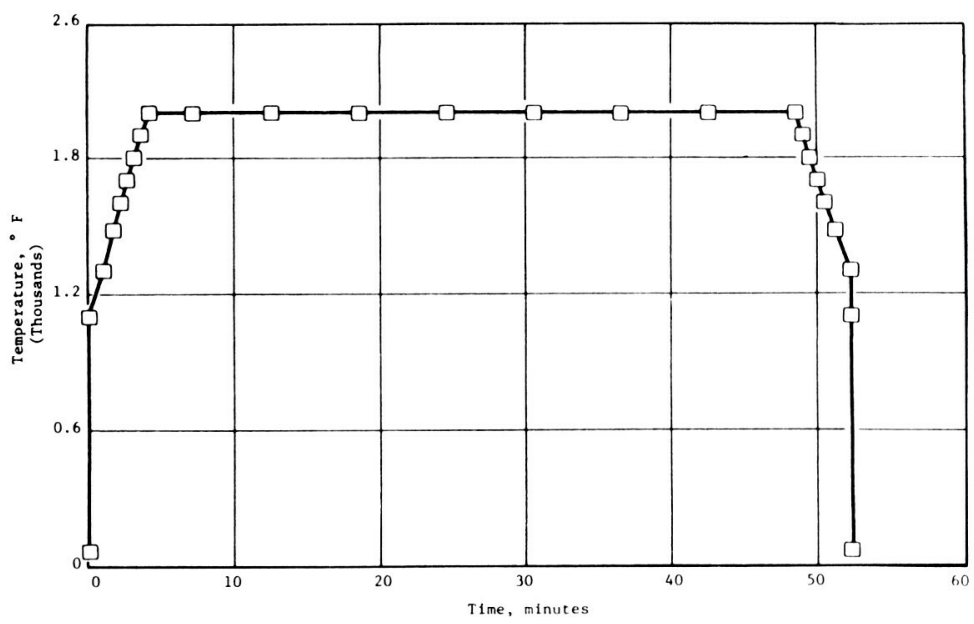

Figure 18. Thermal Loading Cycle. 


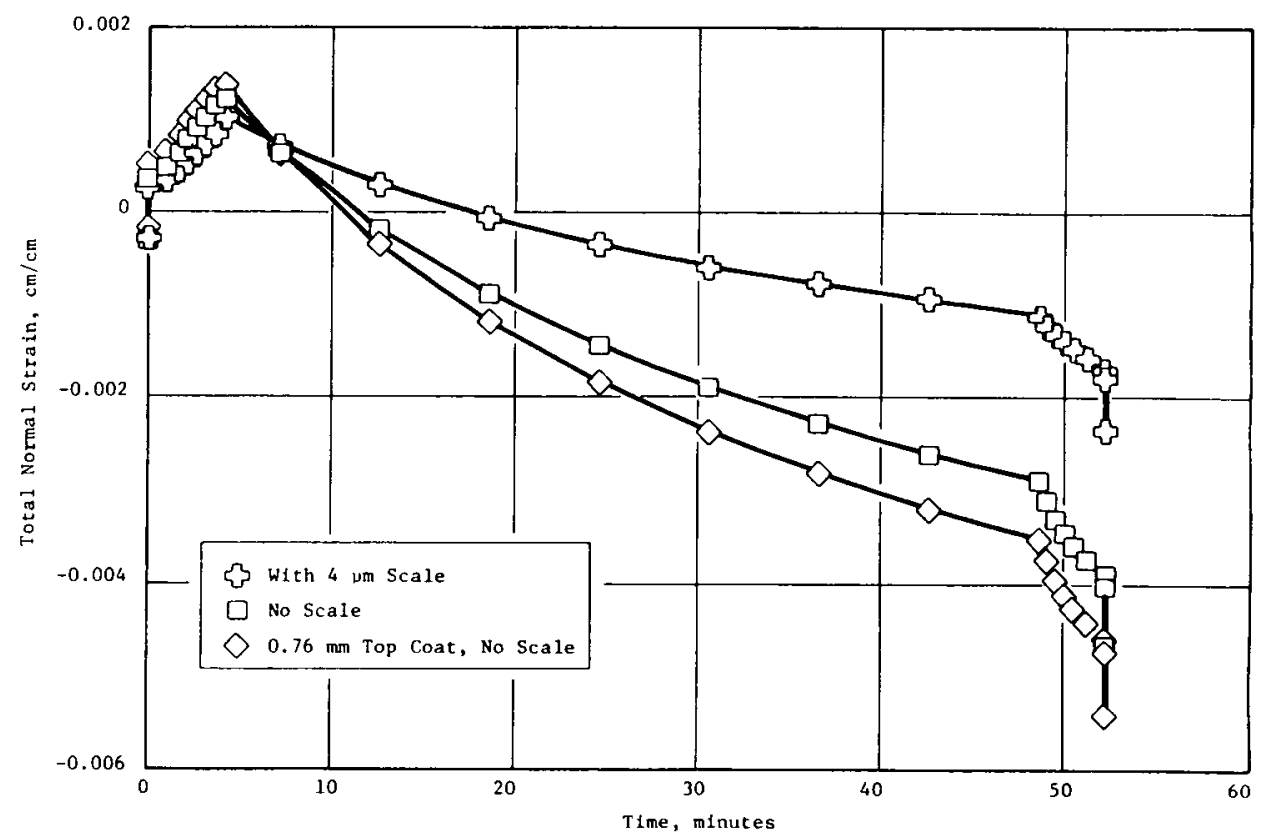

Figure 19. Calculated Total Normal Strain in Top Coat at Top Coat/Bond Coat Interface of Thermal Barrier Coated Tubular Specimen During Thermal Cycle. Bond Coat Thickness $0.13 \mathrm{~mm}$; Top Coat Thickness $0.254 \mathrm{~mm}$ Unless Indicated Otherwise.

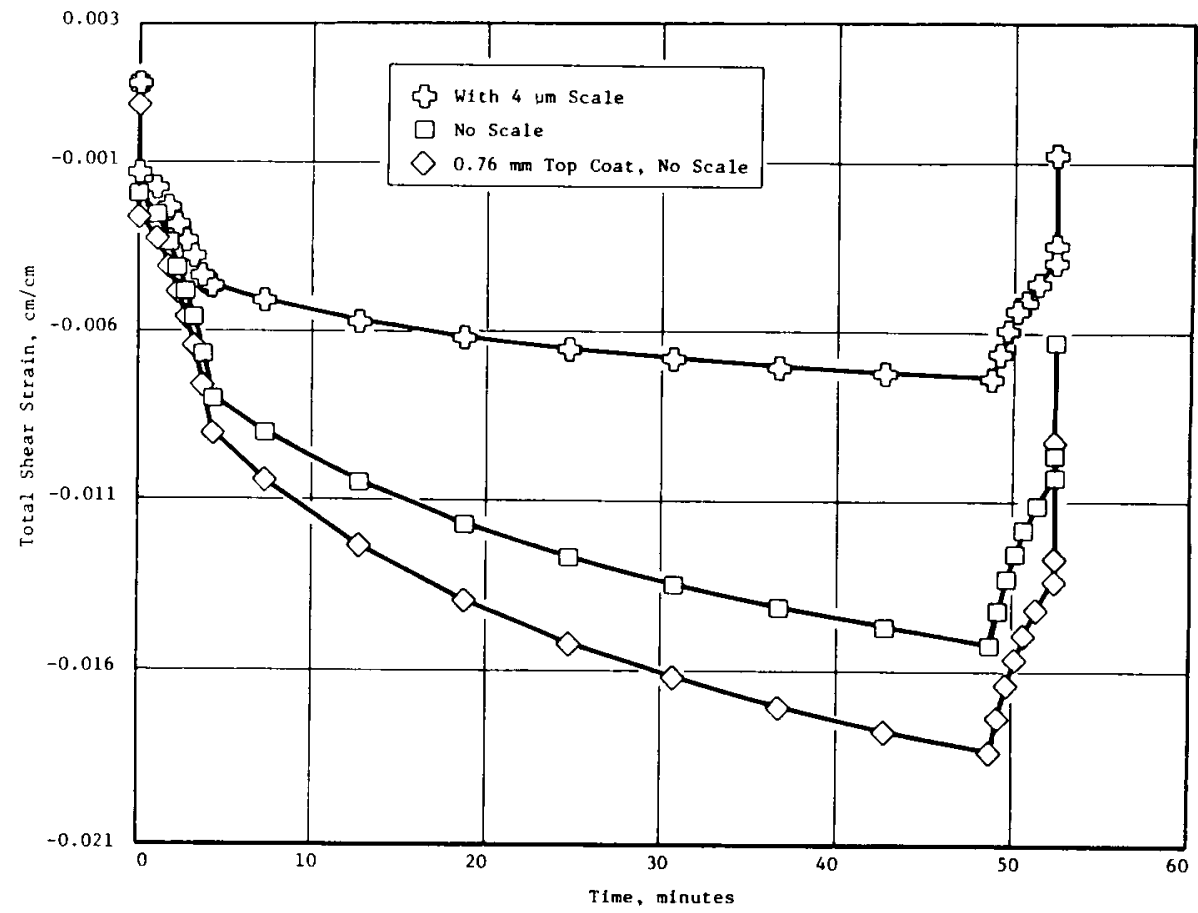

Figure 20. Calculated Total Shear Strain in Top Coat at Top Coat/Bond Coat Interface of Thermal Barrier Coated Tubular Specimen During Thermal Cycle. Bond Coat Thickness $0.13 \mathrm{~mm}$; Top Coat Thickness $0.254 \mathrm{~mm}$ Un less Indicated Otherwise. 


\section{ORIGINAL PAGE IS \\ OF POOR QUALITY}

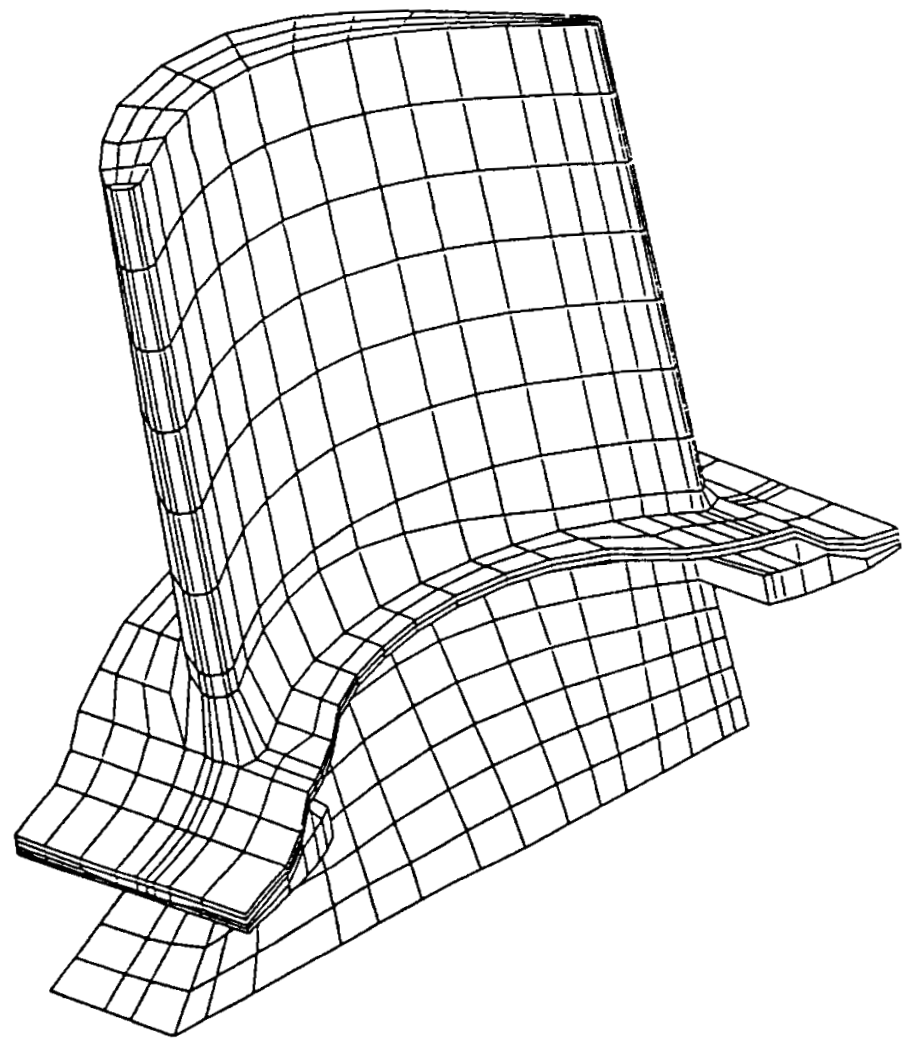

Figure 21. SIESTA Plot of Converted NASA Blade Model. 